\title{
Autoimmune Conditions in 235 Hemochromatosis Probands with HFE C282Y Homozygosity and Their First-Degree Relatives
}

\author{
James C. Barton ${ }^{1,2}$ and J. Clayborn Barton ${ }^{1}$ \\ ${ }^{1}$ Southern Iron Disorders Center, Birmingham, AL 35209, USA \\ ${ }^{2}$ Department of Medicine, University of Alabama at Birmingham, Birmingham, AL 35209, USA \\ Correspondence should be addressed to James C. Barton; ironmd@isp.com
}

Received 18 June 2015; Accepted 2 August 2015

Academic Editor: Fulvia Ceccarelli

Copyright (c) 2015 J. C. Barton and J. C. Barton. This is an open access article distributed under the Creative Commons Attribution License, which permits unrestricted use, distribution, and reproduction in any medium, provided the original work is properly cited.

\begin{abstract}
We performed a retrospective study of autoimmune conditions (ACs) in 235 hemochromatosis probands at diagnosis by analyzing age, sex, ACs, history of first-degree family members with ACs (FH), diabetes, heavy ethanol consumption, elevated serum ALT/AST, nonalcoholic fatty liver disease, viral hepatitis, cirrhosis, iron removed to achieve iron depletion (QFe), and positivity for human leukocyte antigen (HLA) haplotypes $A^{*} 01, B^{*} 08 ; A^{*} 02, B^{*} 44 ; A^{*} 03, B^{*} 07 ; A^{*} 03, B^{*} 14$; and $A^{*} 29, B^{*} 44$. There were 138 men (58.7\%). Median followup was $19.6 \mathrm{y}$. One or more of 19 ACs were diagnosed in each of 35 probands (14.9\%). Prevalences of Hashimoto's thyroiditis, rheumatoid arthritis, and ankylosing spondylitis were 8.1\% (95\% CI: [5.1, 12.5]), 1.7\% [0.6, 4.6], and 0.0085 $[0.0015,0.0337]$, respectively. Eighteen probands (7.7\%) had a FH. Eight probands with ACs had 9 family members with ACs. In a logistic regression, ACs were less likely in men (odds ratio (OR) $0.3[0.1,0.6]$ ) and more likely in probands with a FH (OR 4.1 $[1.4,11.8])$. Overall ACs risk was not significantly associated with QFe or HLA haplotypes. Estimated survival of probands with and without ACs did not differ significantly. We conclude that ACs are common in hemochromatosis probands, especially women and probands with a $\mathrm{FH}$.
\end{abstract}

\section{Introduction}

Hemochromatosis in whites of western European descent is an autosomal recessive disorder that increases the risk to develop iron overload. Severe iron overload can cause cirrhosis, primary liver cancer, diabetes mellitus, other endocrinopathies, and cardiomyopathy $[1,2]$. By 1976, it was discovered that hemochromatosis in most whites is linked to human leukocyte antigen (HLA) $\mathrm{A}^{*} 03$ or HLA haplotypes $\mathrm{A}^{*} 03, \mathrm{~B}^{*} 07$ or $\mathrm{A}^{*} 03, \mathrm{~B}^{*} 14[3,4]$. For two decades thereafter, the combination of iron phenotyping and HLA-A and HLA$\mathrm{B}$ typing was used to diagnose hemochromatosis in probands and first-degree family members [5].

In 1996, it was discovered that $\sim 90 \%$ of whites with hemochromatosis were homozygous for a common mutation (exon 4, c.845G>A, p.C282Y; rs1800562) in a previously undescribed nonclassical class I major histocompatibility complex (MHC) gene on chromosome 6p [6]. The gene, now known as HFE, occurs in linkage disequilibrium with the HLA-A locus $[3,7,8]$. The most common hemochromatosis ancestral haplotypes in many northwestern European and derivative populations include HFE C282Y linked to HLA$\mathrm{A}^{*} 03$ [7-10], HLA-A* 03, B* 07 [7-9], or HLA-A* 03, B* 14 [7$9,11]$. C282Y also occurs on other HLA haplotypes, including $A^{*} 01, B^{*} 08$ and $A^{*} 29, B^{*} 44[7,8,12,13]$.

Autoimmune conditions (ACs) in persons with hemochromatosis have been documented predominantly in case reports, small case series, or studies of single ACs [14-19]. Our informal experience suggested that ACs are relatively common in adults with hemochromatosis. To study this further, we performed a retrospective analysis of ACs at diagnosis of hemochromatosis in 235 nonscreening probands with HFE C282Y homozygosity who had also undergone HLA-A and -B typing. Median followup was $19.6 \mathrm{y}$. We compared characteristics of probands with and without ACs, used univariable and multivariable methods to identify attributes significantly associated with ACs, and estimated survival of probands with and without ACs. We compiled a list of ACs previously 
reported in adults with hemochromatosis. We discuss our observations in the context of prevalence estimates of ACs in general populations and the association of ACs with serum ferritin (SF) and iron removed by phlebotomy to achieve iron depletion (QFe).

\section{Methods}

2.1. Selection of Hemochromatosis Probands. The performance of this work was approved by the Institutional Review Board of Brookwood Medical Center. Obtaining informed consent was not required because information reported herein was documented as part of routine medical care. We performed computerized and manual searches of medical records to identify patients who were evaluated for hemochromatosis in the interval 1976-2014 by the first author because they had elevated values of transferrin saturation or SF detected in medical care (not as part of family or population screening). Each patient selected for this study (a) was a white adult ( $>18$ years of age) and the first in his/her respective family to be diagnosed to have hemochromatosis (proband); (b) had HFE C282Y/C282Y; (c) had undergone HLA-A and -B haplotyping; and (d) resided in central Alabama. Each proband was evaluated for iron overload and associated complications, as appropriate [20].

2.2. Autoimmune Conditions in Probands. We studied ACs diagnosed before hemochromatosis was diagnosed. Probands with ACs were characterized by referring physicians, our queries regarding ACs, medication reviews, interpretation of tissue specimens, and immunologic characteristics. In probands diagnosed to have Hashimoto's thyroiditis (HT), we concurred with diagnoses of HT after reviewing evidence of goiter or hypothyroidism, autoantibodies for thyroid peroxidase, thyroglobulin or thyroid-stimulating hormone receptors, features of thyroid glands typical of HT on pathology reports, use of thyroid hormone supplements, and exclusion or absence of other causes of hypothyroidism. Probands with rheumatoid arthritis had typical clinical manifestations, positive RA latex turbidity tests, and elevated levels of cyclic citrullinated peptide antibodies. We performed confirmatory tests for ACs in some probands.

2.3. Family History of Autoimmune Conditions. Reports of first-degree relatives (parents, full siblings, and children) with ACs (family history, FH) were elicited from each proband and documented at the time of initial evaluation for hemochromatosis. We interviewed first-degree relatives as part of family evaluations and reviewed their medical records or both.

2.4. Diabetes Mellitus in Probands. Probands with diabetes were diagnosed and characterized by referring physicians, our queries regarding diabetes, and medication reviews. Diabetes was defined and subclassified according to the criteria of the American Diabetes Association [21]. We excluded a woman with diabetes because she had undergone pancreatectomy for management of adenocarcinoma of the pancreas.

2.5. Definition of Heavy Ethanol Consumption. Heavy ethanol consumption was defined as the self-reported consumption of $\geq 60 \mathrm{~g}$ ethanol/d for $\geq 5 \mathrm{y}$ [22].

2.6. Definitions of Liver Conditions. Elevated serum alanine aminotransferase (ALT) or aspartate aminotransferase (AST) was defined as a level $>2$ SD above mean (>40 IU/L). Nonalcoholic fatty liver disease (NAFLD) was defined as steatosis or steatohepatitis detected on liver biopsy specimens or by typical increase of hepatic echogenicity detected by ultrasonography, in the absence of self-reports of heavy ethanol consumption [22]. Chronic hepatitis B or C was defined as positivity for $\mathrm{HB}_{\mathrm{s}} \mathrm{Ag}$ or hepatitis $\mathrm{C}$ antibody, respectively, in association with other clinical or liver biopsy abnormalities consistent with chronic viral hepatitis [22]. Liver biopsy was performed in probands with SF $>1000 \mu \mathrm{g} / \mathrm{L}$ and in those suspected to have an undiagnosed non-iron liver disorder. Liver histology and intrahepatocytic iron were evaluated as previously described $[22,23]$. Cirrhosis was defined by pathologists' interpretations of liver biopsy specimens [22].

2.7. Serum Ferritin and Iron Removed by Phlebotomy. SF values $>300 \mu \mathrm{g} / \mathrm{L}$ in men and $>200 \mu \mathrm{g} / \mathrm{L}$ in women were defined as elevated [20]. Iron depletion therapy, defined as the periodic removal of blood to eliminate storage iron, was complete when SF was $\leq 20 \mu \mathrm{g} / \mathrm{L}$ [20]. QFe was estimated as $200 \mathrm{mg}$ Fe per unit of blood (450-500 mL) [20].

2.8. Survival. All probands designated as alive were so confirmed on May 1, 2015. Dates of death were determined by review of medical records, by computerized searches for obituary notices, and by the Social Security Death Index (http://ssdi.rootsweb.ancestry.com/ and https://www.dobsearch.com/death-records/search-ssn.php). Survival after diagnosis was computed using date of diagnosis of hemochromatosis and either May 1, 2015, or date of death, as appropriate. Overall survival was computed using date of birth and either May 1, 2015, or date of death, as appropriate.

2.9. Laboratory Methods. Levels of SF, ALT, AST, $\mathrm{HB}_{\mathrm{s}} \mathrm{Ag}$, $\mathrm{HB}_{\mathrm{s}} \mathrm{Ab}, \mathrm{HB}_{\mathrm{c}} \mathrm{Ab}$, and hepatitis $\mathrm{C}$ antibody were measured using automated clinical methods. HFE mutation analysis was performed as previously described [24]. HLA-A and -B alleles were detected using low-resolution DNA-based typing in probands and family members; haplotypes were ascertained using HLA analyses of appropriate first-degree family members as previously described [7].

2.10. Statistics. SF and QFe values were converted to natural logarithms (ln) to normalize them for analyses; antilns were computed to display mean values (95\% confidence intervals (CI)). The Pearson correlation coefficient of $\operatorname{lnSF}$ with $\ln \mathrm{QFe}$ was 0.4509 (two-tailed test; $p<0.0001$ ). We used QFe as the independent variable representing iron overload severity. Phlebotomy data were incomplete in 20 probands (14 men 
TABLE 1: Comparisons of hemochromatosis probands with and without autoimmune conditions ${ }^{1}$.

\begin{tabular}{|c|c|c|c|}
\hline Characteristic & Autoimmune condition $(n=35)$ & No autoimmune condition $(n=200)$ & Value of $p^{2}$ \\
\hline Mean age, y & $53 \pm 13$ & $48 \pm 13$ & 0.0747 \\
\hline Men, $\%$ & $28.6(10)$ & $64.0(128)$ & $<0.0001$ \\
\hline Family history, $\%(n)^{3}$ & $22.9(8)$ & $5.0(10)$ & 0.0002 \\
\hline Diabetes mellitus, \% ( $n)$ & $14.3(5)$ & $14.0(28)$ & 0.9642 \\
\hline Heavy ethanol, \% (n) & $5.7(2)$ & $14.0(28)$ & 0.1754 \\
\hline Elevated ALT, $\%(n)^{4}$ & $20.0(7)$ & $25.0(50)$ & 0.5243 \\
\hline Elevated AST, $\%(n)^{4}$ & $25.7(9)$ & $28.0(56)$ & 0.7803 \\
\hline NAFLD, $\%(n)$ & $17.1(6)$ & $19.0(38)$ & 0.7950 \\
\hline Viral hepatitis, \% ( $n)$ & $2.9(1)$ & $5.0(10)$ & 0.4922 \\
\hline Cirrhosis, \% $(n)$ & $14.3(5)$ & $10.0(20)$ & 0.4481 \\
\hline Mean SF, $\mu \mathrm{g} / \mathrm{L}$ & $551[72,4202]$ & $807[133,4879]$ & 0.0441 \\
\hline Mean FeQ, g ${ }^{5}$ & $1.7[1.1,2.5]$ & $2.0[1.7,2.4]$ & 0.3962 \\
\hline HLA-A ${ }^{*} 03$ positivity, $\%(n)$ & $77.1(27)$ & $71.5(143)$ & 0.4911 \\
\hline HLA-A ${ }^{*} 01, B^{*} 08$ positivity, $\%(n)$ & $14.3(5)$ & $11.0(22)$ & 0.5739 \\
\hline HLA-A ${ }^{*} 02, \mathrm{~B}^{*} 44$ positivity, $\%(n)$ & $11.4(4)$ & $9.0(18)$ & 0.4911 \\
\hline HLA-A ${ }^{*} 03, \mathrm{~B}^{*} 07$ positivity, $\%(n)$ & $48.6(17)$ & $41.0(82)$ & 0.4026 \\
\hline HLA-A ${ }^{*} 03, \mathrm{~B}^{*} 14$ positivity, $\%(n)$ & $22.9(8)$ & $15.5(31)$ & 0.2805 \\
\hline HLA-A ${ }^{*} 29, \mathrm{~B}^{*} 44$ positivity, $\%(n)$ & 0 & $5.5(11)$ & 0.1626 \\
\hline
\end{tabular}

${ }^{1}$ ALT, alanine aminotransferase; AST, aspartate aminotransferase; NAFLD, nonalcoholic fatty liver disease; SF, serum ferritin; FeQ, iron removed by phlebotomy to achieve iron depletion; HLA, human leukocyte antigen. Mean results are displayed as mean \pm SD or mean $[95 \% \mathrm{CI}]$.

${ }^{2}$ These are nominal values of $p$. Bonferroni correction for 18 comparisons yielded a revised $p$ for significance of $<0.0028$.

${ }^{3}$ History of autoimmune condition(s) in one or more first-degree family members.

${ }^{4}$ Elevated values were defined as $>40 \mathrm{IU} / \mathrm{L}$.

${ }^{5}$ These observations represent 215 probands because phlebotomy data were incomplete in 20 probands.

and 6 women; 8.5\%) and thus their QFe data were not used for analyses.

The final analytic data set consisted of observations on 235 probands. Logistic regressions were performed to identify independent variables significantly associated with ACs and HT. We did not use logistic technique to assess predictors of rheumatoid arthritis, ankylosing spondylitis, or other ACs because logistic models suffer from small sample bias [25]. Independent variables appropriate for most regression analyses were age, sex, FH, diabetes mellitus, heavy ethanol consumption, elevated ALT/AST, NAFLD, viral hepatitis, cirrhosis, $\mathrm{QFe}$, and positivity for HLA haplotypes $\mathrm{A}^{*} 01$, $\mathrm{B}^{*} 08 ; \mathrm{A}^{*} 02, \mathrm{~B}^{*} 44 ; \mathrm{A}^{*} 03, \mathrm{~B}^{*} 07 ; \mathrm{A}^{*} 03, \mathrm{~B}^{*} 14$; and $\mathrm{A}^{*} 29, \mathrm{~B}^{*} 44$. We used backward stepwise multiple regression to identify predictors of SF. We used Kaplan-Meier technique (logrank test) to estimate survival and Cox proportional hazards models to identify significant contributors to death.

General descriptive data are presented as enumerations, percentages, mean \pm 1 standard deviation (SD), or mean [ $95 \%$ $\mathrm{CI}$ ]. Univariable comparisons between groups were evaluated using Student's $t$-test, Pearson's $X^{2}$ test, and Fisher's exact test, as appropriate. We expressed some results as odds ratios (OR [95\% CI]). We computed the $95 \%$ CI of proportions with continuity corrections. Values of $p<0.05$ were defined as significant. Bonferroni corrections were applied to control type I error rate at 0.05 for multiple comparisons of continuous and dichotomous data, as appropriate. Analyses were performed with a computer spreadsheet (Excel 2000, Microsoft Corp., Redmond, WA) and a statistical program
(GB-Stat, v. 10.0, 2000, Dynamic Microsystems, Inc., Silver Spring, MD).

2.11. Literature Search. We performed a computerized search of the National Library of Medicine database to identify previous reports of ACs in persons with hemochromatosis. We used two terms per search: the first was the name of an AC and the second was hemochromatosis. Reports were reviewed to verify the diagnosis of hemochromatosis defined as an adult-onset condition typical of HFE hemochromatosis in whites of western European descent characterized by iron phenotyping, HLA typing or haplotyping, or HFE C282Y homozygosity.

\section{Results}

3.1. General Characteristics of 235 Probands. The mean age at diagnosis of hemochromatosis was $49 \pm 13 \mathrm{y}$. There were 138 men (58.7\%). One or more ACs were diagnosed in each of 35 probands (14.9\%; [10.7, 20.2]). The proportion of men was lower among 35 probands with ACs than among 200 probands without ACs (Table 1). Eighteen probands (7.7\%; $[4.7,12.0])$ had a FH of ACs. The proportion of probands with a FH was greater among those with ACs (Table 1). Prevalences of other characteristics did not differ significantly between probands with and without ACs (Table 1). The previous diagnosis of primary biliary cirrhosis was confirmed in one of 102 probands who underwent liver biopsy at the time of 
hemochromatosis diagnosis. No proband was diagnosed to have anterior pituitary or myocardial siderosis.

Mean SF at diagnosis of hemochromatosis was $761 \mu \mathrm{g} / \mathrm{L}$ $[677,858] . \mathrm{SF}>300 \mu \mathrm{g} / \mathrm{L}$ was observed in 131 men $(94.9 \%)$. Of these, 124 (89.9\%) achieved iron depletion. SF > $200 \mu \mathrm{g} / \mathrm{L}$ was observed in 86 women $(88.7 \%)$. Of these, 91 (93.8\%) achieved iron depletion. Phlebotomy data were incomplete in 20 probands (Table 1). Mean QFe in 215 probands was $2.0 \mathrm{~g}$ $[1.7,2.3]$. Mean QFe in probands with and without ACs did not differ significantly (Table 1 ).

3.2. Autoimmune Conditions in 35 Probands. Nineteen different ACs were diagnosed in 35 probands. HT was diagnosed in 19 of 35 probands with ACs (54.3\%) (Table 2). The female: male ratio among probands with $\mathrm{HT}$ was 2.8 . The prevalence of HT was greater in women than men (14.4\% versus $3.6 \%$, resp.; $p=0.0031$; OR $4.6[1.6,13.1])$. Positivity for HLA$\mathrm{A}^{*} 03$ or HLA haplotypes did not differ significantly between 19 probands with HT and 216 probands without HT (data not shown). Among 216 probands without HT, 16 (7.4\%; [4.4, 12.0]) had one or more ACs. No proband was diagnosed to have an autoimmune polyendocrine syndrome or diabetes mellitus type 1 .

3.3. Ankylosing Spondylitis and HLA-B*27 Positivity. Heterozygosity for $\mathrm{B}^{*} 27$ was detected in 16 probands $(6.8 \%)$. Homozygosity for $\mathrm{B}^{*} 27$ was not observed. Neither of two probands with ankylosing spondylitis was positive for $\mathrm{B}^{*} 27$. Only one proband with an AC, a man with $\mathrm{HT}$, was positive for $\mathrm{B}^{*} 27$. Positivity for $\mathrm{B}^{*} 27$ in the present 235 probands and in 1318 central Alabama white control subjects [7] did not differ significantly (0.0681 versus 0.0895 , resp.; $p=$ 0.2808 ). Eight probands had either two $B^{*} 07$ alleles, two $B^{*} 14$ alleles, or one of each, as part of ancestral hemochromatosis haplotypes. Accordingly, only 227 probands would have been "at risk" for inheritance of $\mathrm{B}^{*} 27$. Even with this correction, the difference in positivity for $\mathrm{B}^{*} 27$ in 227 probands and in 1318 control subjects was not significant (0.0705 versus 0.0895, resp.; $p=0.3464$ ).

3.4. Autoimmune Conditions in First-Degree Family Members. Eighteen probands had 19 family members with ACs, among which HT was the most prevalent (Table 3). The proportion of female relatives with ACs $(16 / 19 ; 84.2 \%)$ was greater than the proportion of male relatives with ACs $(3 / 19 ; 15.8 \%)(p<$ $0.0001)$.

Eight probands with ACs had 9 family members who also had ACs. There was concordance for specific ACs in at least two generations in 7 of the 8 kinships: HT (four kinships) and Crohn's disease, Graves' disease, and sarcoidosis (one kinship each). In one kinship, both a female proband and her mother, also a C282Y homozygote, had HT.

3.5. Predictors of Autoimmune Conditions. We performed an initial regression on ACs using 16 appropriate independent variables. In a refined model that included only two variables, there was a negative association of male sex with ACs ( $p=$ 0.0010 ; OR $0.3[0.1,0.6])$. There was a positive association of
TABLE 2: Autoimmune conditions in 35 hemochromatosis probands ${ }^{1}$.

\begin{tabular}{|c|c|}
\hline Condition & Percentage $(n)$ \\
\hline Hashimoto's thyroiditis $^{2}$ & $54.3(19)$ \\
\hline Rheumatoid arthritis ${ }^{3}$ & $11.4(4)$ \\
\hline Ankylosing spondylitis ${ }^{4}$ & $5.7(2)$ \\
\hline Mixed connective tissue disorder & $5.7(2)$ \\
\hline Myasthenia gravis & $5.7(2)$ \\
\hline Pernicious anemia & $5.7(2)$ \\
\hline Sarcoidosis & $5.7(2)$ \\
\hline Ulcerative colitis & $5.7(2)$ \\
\hline Autoimmune hemolytic anemia ${ }^{5}$ & $2.9(1)$ \\
\hline Crohn's disease & $2.9(1)$ \\
\hline Elevated antinuclear antibody ${ }^{6}$ & $2.9(1)$ \\
\hline Graves' disease & $2.9(1)$ \\
\hline Polymyalgia rheumatica & $2.9(1)$ \\
\hline Primary biliary cirrhosis & $2.9(1)$ \\
\hline Psoriasis & $2.9(1)$ \\
\hline Raynaud's phenomenon & $2.9(1)$ \\
\hline Scleroderma & $2.9(1)$ \\
\hline Sjögren’s syndrome & $2.9(1)$ \\
\hline Systemic lupus erythematosus & $2.9(1)$ \\
\hline
\end{tabular}

${ }^{1}$ Six probands had two or more autoimmune conditions. Two men had both Hashimoto's thyroiditis and pernicious anemia. One woman had both Hashimoto's thyroiditis and Crohn's disease. One woman had Hashimoto's thyroiditis, polymyalgia rheumatica, and systemic lupus erythematosus. One woman had Hashimoto's thyroiditis, Raynaud's phenomenon, sarcoidosis, scleroderma, and Sjögren's syndrome. One woman had both ulcerative colitis and biliary cirrhosis.

${ }^{2}$ Of 235 probands, 14 women and 5 men had Hashimoto's thyroiditis $(8.1 \%[5.1,12.5])$.

${ }^{3}$ Of 235 probands, 2 men and 2 women had rheumatoid arthritis (1.7\% [0.6, 4.6]).

${ }^{4}$ Of 235 probands, 2 men had ankylosing spondylitis (0.0085 [0.0015, $0.0337])$.

${ }^{5}$ Mediated by IgG and complement.

${ }^{6}$ This proband had anti-nuclear antibody $>1: 320$ without other manifestation of autoimmunity. Elevated anti-nuclear antibodies $(>1: 80)$ in other probands were interpreted as part of broader autoimmune condition diagnoses named separately.

FH with ACs $(p=0.0093$; OR $4.1[1.4,11.8])$. This 2-factor model explained $11.0 \%$ of total deviance contributing to ACs $\left(X^{2}=21.69 ; p<0.0001\right)$.

3.6. Predictors of Hashimoto's Thyroiditis. We performed an initial regression on HT using 16 appropriate independent variables. The variables age, male sex, FH, and QFe were used in a final model. There was a negative association with male sex $(p=0.0216$; OR $0.3[0.1,0.8])$. There was a positive association of HT with FH ( $p=0.0323$; OR 3.8 [1.1, 13.0]). This 4 -factor model explained $13.0 \%$ of total deviance contributing to HT $\left(X^{2}=17.16 ; p=0.0018\right)$.

3.7. Predictors of Autoimmune Conditions other than Hashimoto's Thyroiditis. We performed a logistic regression on ACs after removing observations on 19 probands with HT from the analytic dataset. An initial regression included 16 
TABLE 3: Autoimmune conditions in 18 first-degree relatives of 235 hemochromatosis probands ${ }^{1}$.

\begin{tabular}{lccc}
\hline Conditions in relatives & 35 probands with autoimmune conditions & 200 probands without autoimmune conditions & Value of $p^{2}$ \\
\hline Hashimoto's thyroiditis & $11.4(4)$ & $0.5(1)$ & 0 \\
Crohn's disease & $5.7(2)$ & $0.5(1)$ & 0.0216 \\
Graves' disease & $2.9(1)$ & $2.0(4)$ & 0.2762 \\
Rheumatoid arthritis & $2.9(1)$ & 0 & 0.5569 \\
Sarcoidosis & $2.9(1)$ & 0 & 0.1489 \\
Vitiligo & $2.9(1)$ & $0.5(1)$ & 0.1489 \\
Addison's disease & 0 & $0.5(1)$ & 0.8511 \\
Multiple sclerosis & 0 & $0.5(1)$ & 0.8511 \\
Pernicious anemia & 0 & $0.5(1)$ & 0.8511 \\
Scleroderma & 0 & 0.8511 \\
\hline
\end{tabular}

${ }^{1}$ Observations are displayed as \% $(n)$ of the proband subgroups who had first-degree relatives with the indicated conditions. Each of two relatives had two autoimmune conditions.

${ }^{2}$ These are nominal values of $p$. Bonferroni correction for 10 comparisons yielded a revised $p$ for significance of $<0.0050$.

appropriate independent variables. Age, male sex, FH, and QFe were appropriate for a final model. The only significant (negative) predictor was male sex ( $p=0.0261$; OR 0.3 [0.1, $0.9]$ ). This 4 -factor model explained $9.7 \%$ of total deviance contributing to ACs other than HT $\left(X^{2}=11.12 ; p=0.0252\right)$.

3.8. Predictors of Serum Ferritin. We performed a backwards stepwise regression on SF using 16 independent variables. There were significant positive associations with male sex $(p<0.0001)$; diabetes $(p=0.0403)$; elevated AST $(p=$ $0.0375)$; and cirrhosis $(p<0.0001)$. There was a significant negative association with HLA-A* $01, B^{*} 08(p=0.0047)$. This 5 -factor model explained $23.6 \%$ of total deviance contributing to SF (ANOVA $p=0.0252$ ).

3.9. Survival. Median survival after diagnosis of hemochromatosis was $19.6 \mathrm{y}$ (mean $18.5 \pm 7.7 \mathrm{y}$ ). Median overall survival was $68.0 \mathrm{y}$ (mean $66.8 \pm 14.8 \mathrm{y}$ ). There were 40 deaths (27 men, 13 women) (17.0\%). No death was attributed to direct or indirect consequences of ACs.

Kaplan-Meier estimates of survival after hemochromatosis diagnosis of probands with and without ACs were similar $(p=0.6380$ ) (Figure 1). Cox proportional hazards analysis revealed two positive associations with death: age $(p=$ $0.0107)$ and $\mathrm{QFe}(p=0.0032)$. Overall survival of probands with and without ACs was also similar $(p=0.1127)$ (Figure 1). Cox proportional hazards analysis revealed two positive associations with death: heavy ethanol consumption $(p=0.0228)$ and cirrhosis $(p=0.0096)$. Comparison of survival after hemochromatosis diagnosis or overall survival of men with and without ACs and of women with and without ACs revealed no significant differences (data not shown).

3.10. Autoimmune Conditions Previously Reported in Persons with Hemochromatosis. These ACs are displayed in Table 4.

\section{Discussion}

The present results demonstrate that $14.9 \%$ of 235 hemochromatosis probands with HFE C282Y homozygosity had one or
TABLE 4: Autoimmune conditions previously reported in persons with hemochromatosis ${ }^{1}$.

\begin{tabular}{|c|c|}
\hline Condition & Reference \\
\hline Autoimmune hemolytic anemia & {$[14]$} \\
\hline Celiac disease & {$[17,19,26-29]$} \\
\hline Diabetes mellitus type $1^{2}$ & [30] \\
\hline Hashimoto's thyroiditis & {$[16,31,32]$} \\
\hline Hyperthyroidism or Graves' disease & {$[16,33-35]$} \\
\hline Immune thrombocytopenia & [34] \\
\hline Myasthenia gravis ${ }^{3}$ & {$[36]$} \\
\hline Pernicious anemia & {$[37,38]$} \\
\hline Psoriasis & [39] \\
\hline Rheumatoid arthritis & {$[40,41]$} \\
\hline Sarcoidosis ${ }^{4}$ & {$[18,42]$} \\
\hline Schnitzler's syndrome & {$[43]$} \\
\hline Sclerosing cholangitis ${ }^{5}$ & {$[44]$} \\
\hline Ulcerative colitis ${ }^{5}$ & {$[44]$} \\
\hline Vitiligo & {$[15]$} \\
\hline
\end{tabular}

$\overline{{ }^{1} \text { Hemochromatosis was defined as an adult-onset condition typical of }}$ HFE hemochromatosis in European white adults characterized by iron phenotyping, HLA typing or haplotyping, or HFE C282Y homozygosity. One HFE C282Y homozygote had collagenous sprue, a rare condition of uncertain etiology [45].

${ }^{2}$ Autoimmunity was not mentioned in descriptions of study subjects.

${ }^{3}$ This man had pure red cell aplasia of undefined cause.

${ }^{4}$ The case of a woman with sarcoidosis included herein was reported previously [18].

${ }^{5}$ Ulcerative colitis and sclerosing cholangitis occurred in the same man.

more of 19 different ACs at diagnosis of hemochromatosis. ACs were more likely to occur in women and in probands with first-degree relatives who had ACs. HT was diagnosed in $54 \%$ of probands with ACs. Among 216 probands without HT, 7.4\% had ACs that were positively associated with women. Overall risk of ACs was not significantly associated with QFe. ACs were not significantly associated with positivity for HLA-A*03 or HLA-A and -B haplotypes, including the $A^{*} 01, B^{*} 08$ haplotype associated elsewhere with ACs [46]. 


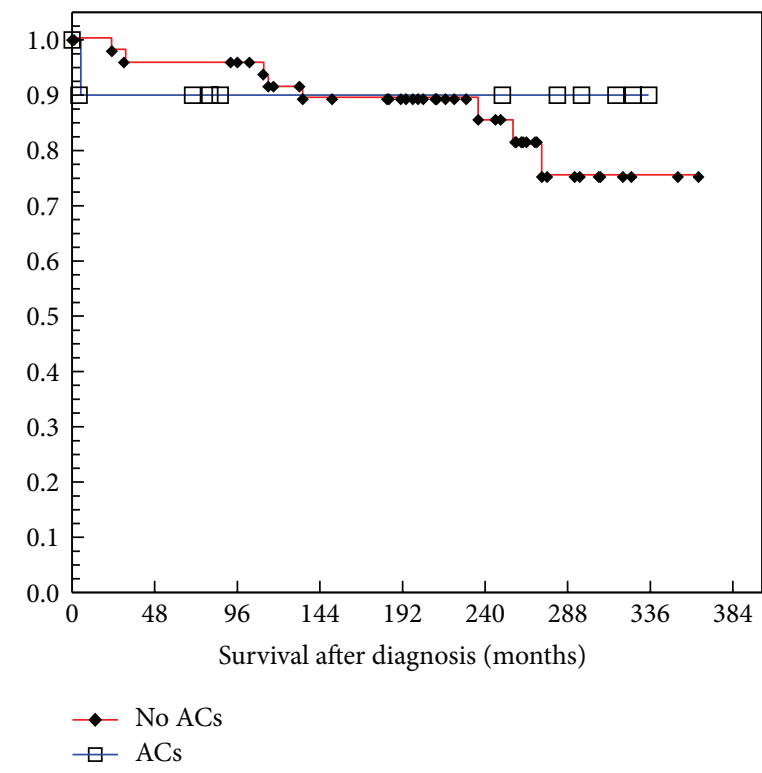

(a)

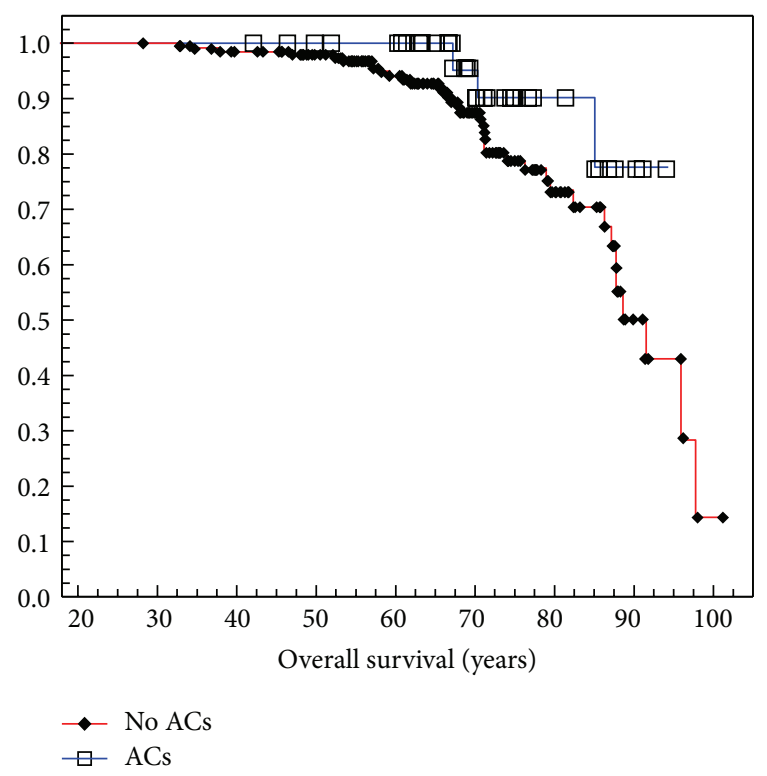

(b)

FIGURE 1: (a) Kaplan-Meier estimates of survival after hemochromatosis diagnosis in probands with and without autoimmune conditions (ACs) $(p=0.6380$; log-rank test). (b) Kaplan-Meier estimates of overall survival of hemochromatosis probands with and without ACs $(p=0.1127 ;$ log-rank test).

Estimated survival of probands with and without ACs did not differ significantly.

Population prevalence rates for ACs vary for many reasons [47], including underrepresentation of certain ACs in study cohorts $[47,48]$, high prevalence of undiagnosed ACs [49], lack of prevalence data for some ACs [47], and differences across race/ethnicity groups or geographic regions [48]. The combined prevalence of $24 \mathrm{ACs}$ in persons unselected for hemochromatosis diagnoses was 3.2\% [50]. The combined prevalence of $31 \mathrm{ACs}$ in hospitalized Danes was more than $5 \%$ [48]. In 2009, Cooper and colleagues, using "adjustments" to these prevalence assessments $[48,49]$, estimated that the overall population prevalence of ACs is 9.4\% [47]. These observations suggest that the combined prevalence of ACs in the present probands of $14.9 \%(10.7,20.2)$ is similar to that in populations not selected for hemochromatosis diagnoses.

The prevalence of HT in the present probands was $8.1 \%$ $(5.1,12.5)$. In women aged $20-49 \mathrm{y}$ in a large population hemochromatosis screening program in Norway, $12.5 \%$ of HFE C282Y homozygotes and 3.0\% of control participants reported having hypothyroidism [51]. In the Hemochromatosis and Iron Overload Screening Study of adult primary care participants in North America, 8.5\% of 176 HFE C282Y homozygotes and $10.9 \%$ of $312 \mathrm{HFE}$ wt/wt controls reported taking thyroid supplements $(p=0.4019)$ [52]. Prevalence estimates for untreated hypothyroidism did not differ significantly between C282Y homozygotes (1.7\%) and controls $(1.3 \%)$ or between male and female C282Y homozygotes and corresponding controls [52]. The prevalence of HT confirmed by cytology in 811 consecutive patients unselected for hemochromatosis diagnoses who underwent fine-needle aspiration of thyroid nodules was $13.4 \%$, of whom $5.7 \%$
(4.1, 7.4) were clinically hypothyroid [53]. Although some differences in prevalence estimates of HT or presumed HT are due to dissimilarities in study design and case ascertainment, we infer that prevalences of HT in hemochromatosis probands diagnosed in medical care and in HFE C282Y homozygotes identified in screening are similar to those in other populations [53].

HT was significantly associated with the present female probands in univariable and multivariable analyses. The female: male ratio of HT was 2.8. In other studies, female: male ratios of autoimmune thyroiditis were 5.1-9.1 [54]. In a meta-analysis, skewed $\mathrm{X}$-inactivation was significantly greater in women with HT than in control subjects. This could explain in part the preponderance of women in HT cohorts [55]. On the other hand, English gerontologist Joseph Sheldon did not describe thyromegaly, lymphocytic infiltrates, or other attributes of autoimmune thyroiditis in his 1935 monograph of 311 hemochromatosis cases [56]. It is plausible that gross and microscopic manifestations typical of autoimmune thyroiditis were obscured by thyroid fibrosis attributed to iron deposits or were not detected because women represented only $5 \%$ of the cases [56].

The prevalence of rheumatoid arthritis in the present probands $(1.7 \%[0.6,4.6])$ is similar to that in the U.S. general adult population $(0.5-1.0 \%)[57,58]$. Some manifestations of hand arthropathy due to hemochromatosis and rheumatoid arthritis are similar [59]. To distinguish these conditions, it is prudent to perform an immunologic evaluation for rheumatoid arthritis in patients with hemochromatosis and hand arthropathy $[40,41,59]$.

The prevalence of ankylosing spondylitis in the present probands $(15-337 / 10,000)$ is similar to that of $32 / 10,000$ in 
North American subjects unselected for hemochromatosis or HFE C282Y homozygosity [60]. HLA-B* 27 positivity rates in the present probands, in white control subjects from central Alabama [7], and in Caucasian control subjects in the US [61] are similar (7-9\%). Neither of the two present probands diagnosed to have ankylosing spondylitis was positive for $\mathrm{B}^{*} 27$, whereas $80-95 \%$ of persons with ankylosing spondylitis worldwide are $B^{*} 27$-positive [62]. We attribute this difference to the small sample size of probands with ankylosing spondylitis in the present study. There are radiographic similarities and dissimilarities in spine manifestations of ankylosing spondylitis and hemochromatosis [63].

QFe was not significantly associated with ACs in the present study. In contrast, the prevalence of autoimmune thyroid disorders in 34 men homozygous for hemochromatosis alleles $(8.8 \%)$ was higher than in the general male population [16]. Although it has been postulated that iron deposits in the thyroid glands of persons with hemochromatosis cause HT or Graves' disease [16, 31, 64], this postulate remains unproven. Iron deposits were detected in the thyroid glands of a majority of persons with hemochromatosis studied at autopsy [56, 64, 65]. Among 391 persons with hemochromatosis diagnosed in medical care, only $4.1 \%$ had primary hypothyroidism and only $0.3 \%$ had hyperthyroidism $[16,66-$ 69]. Thus, it is unlikely that iron deposits in the thyroid gland contribute to the pathogenesis of hypothyroidism or hyperthyroidism in most persons with hemochromatosis. There are few well-documented hemochromatosis patients who had hypothyroidism due to impaired thyrotroph function. Most of them also had hypogonadotropic hypogonadism [70-74]. Iron deposits were visualized in a minority of thyrotrophs in some persons with severe iron overload due to hemochromatosis. The deposits were much less prominent than those in gonadotrophs $[64,75]$. In rare cases, secondary hypothyroidism resolved after iron depletion $[72,74]$.

There was intraperson co-occurrence of two or more ACs in six probands, five of whom had HT. Persons with HT unselected for hemochromatosis diagnoses also have increased risk for co-occurrence of other ACs, including Addison's disease [76, 77]; autoimmune hepatitis [78]; celiac disease [76, 79]; diabetes mellitus type 1 [80-82]; mixed connective tissue disorder [83]; multiple sclerosis [33]; pernicious anemia [76, 77]; polymyositis/dermatomyositis [83]; rheumatoid arthritis $[33,83]$; Sjögren's syndrome [83]; systemic lupus erythematosus [76, 83]; systemic sclerosis [83]; and vitiligo [76]. One of the present probands, a woman, had both ulcerative colitis and biliary cirrhosis. Co-occurrence of these conditions in the same individual is uncommon but well documented [8486].

There was co-occurrence of specific ACs in two (or three) generations in seven of the present kinships, including four kinships with HT. Familial clusters of specific ACs occur, depending upon the proband's specific AC $[47,87]$. There is strong familial clustering of autoimmune thyroid disease in kinships unselected for hemochromatosis diagnoses [88, 89]. It is also more feasible to detect statistically significant associations with autoimmune thyroid conditions than associations with ACs that are less common [47].
SF levels were elevated in $92 \%$ of the present probands and in some patients with ACs who were not selected for hemochromatosis diagnoses [90]. ACs were not significant predictors of SF in the present study. SF is a mixture of ironrich ferritin and apoferritin $[91,92]$. The iron composition of SF is increased in hemochromatosis and other iron overload disorders, consistent with the function of ferritin as an iron storage protein [91, 93]. It cannot be determined whether increased amounts of apoferritin were released into the blood of some of the present probands as acute phase reactants due to inflammation or interleukin-1 [92, 94].

Survival estimates in probands with and without ACs did not differ significantly. Although ACs are among the leading causes of death in young and middle-age women in the US [95], death of none of the 40 present probands was attributed to consequences of ACs. Decreased survival after diagnosis of hemochromatosis was significantly associated with age at diagnosis and QFe. Decreased overall survival was significantly associated with heavy ethanol consumption and cirrhosis. These outcomes are consistent with previous reports of survival of patients with hemochromatosis unselected for diagnoses of ACs [11, 22, 96].

ACs in two or more previous reports (HT, Graves' disease, rheumatoid arthritis, pernicious anemia, and sarcoidosis) mirror the relative prevalences of the corresponding ACs in the present probands. We may have missed other reports of ACs in persons with hemochromatosis because the search terms we used did not correspond to the key words for indexing the reports. There are multiple reports of the concurrence of hemochromatosis and celiac disease [17, 19, 26-29]. Although hemochromatosis was associated with an increased risk of celiac disease in one study [19], none of the present probands was diagnosed to have celiac disease.

There are uncertainties in the present results. Our enumerations and prevalence estimates of ACs are conservative because some probands may have failed to report or their medical records did not document that they had ACs or FH of ACs. Some persons with HT are euthyroid or have subclinical hypothyroidism [54] and thus their thyroiditis may have been unrecognized at the time of hemochromatosis diagnosis. Followup of each proband for the possible development of ACs after hemochromatosis diagnosis was beyond the scope of the present study, although we observed informally that two probands developed HT several years after they achieved iron depletion. Many ACs have been described in insufficient numbers of persons with hemochromatosis to permit meaningful prevalence estimates. The reliability of $\mathrm{FH}$ reports in previous studies of ACs [88, 89], especially when medical records were available [97], was excellent. Complete QFe data were not available in 20 of the present probands. Based on the results of univariable comparisons and regression analyses of QFe observations in the other 215 probands, it is unlikely that the present results would have differed significantly had QFe data been available for all probands. The present observations cannot exclude the possibility that MHC-linked genes, including some loci linked to HLA-A and -B $[46,98]$, contributed to the pathogenesis of ACs in the present probands. HLA characteristics of HFE C282Y homozygotes that reside in other geographic 
areas may differ from those of the present probands. It is plausible but unproven that diagnosis and management of ACs increase the likelihood that a HFE C282Y homozygote would be diagnosed subsequently to have hemochromatosis.

\section{Conclusions}

We conclude that ACs are common in hemochromatosis probands, especially women and probands with a FH. Overall risk of ACs is not significantly associated with QFe or HLA haplotypes.

\section{Abbreviations}

ACs: Autoimmune conditions

ALT: Serum alanine aminotransferase

AST: Serum aspartate aminotransferase

CI: Confidence interval

FH: History of autoimmune conditions in first-degree family members

HLA: Human leukocyte antigen

HT: Hashimoto's thyroiditis

MHC: Major histocompatibility complex

OR: Odds ratio

QFe: Quantity of iron removed by phlebotomy to achieve iron depletion

SD: $\quad$ Standard deviation

SF: $\quad$ Serum ferritin.

\section{Conflict of Interests}

The authors declare that there is no conflict of interests regarding the publication of this paper.

\section{Acknowledgment}

This work was supported in part by Southern Iron Disorders Center.

\section{References}

[1] S. C. Finch and C. A. Finch, "Idiopathic hemochromatosis, an iron storage disease. A. Iron metabolism in hemochromatosis," Medicine, vol. 34, no. 4, pp. 381-430, 1955.

[2] C. Q. Edwards and J. C. Barton, "Hemochromatosis," in Wintrobe's Clinical Hematology, J. P. Greer, D. A. Arber, B. Glader et al., Eds., chapter 25, pp. 662-681, Wolters Kluwer/Lippincott Williams \& Wilkins, Philadelphia, Pa, USA, 2014.

[3] M. Simon, Y. Pawlotsky, M. Bourel, R. Fauchet, and B. Genetet, "Letter: Idiopathic hemochromatosis associated with HL-A 3 tissular antigen," La Nouvelle Presse Médicale, vol. 4, no. 19, article 1432, 1975.

[4] M. Simon, M. Bourel, R. Fauchet, and B. Genetet, "Association of HLA-A3 and HLA-B14 antigens with idiopathic haemochromatosis," Gut, vol. 17, no. 5, pp. 332-334, 1976.

[5] C. Q. Edwards, L. M. Griffin, D. Goldgar, C. Drummond, M. H. Skolnick, and J. P. Kushner, "Prevalence of hemochromatosis among 11,065 presumably healthy blood donors," The New England Journal of Medicine, vol. 318, no. 21, pp. 1355-1362, 1988.
[6] J. N. Feder, A. Gnirke, W. Thomas et al., "A novel MHC class I-like gene is mutated in patients with hereditary haemochromatosis," Nature Genetics, vol. 13, no. 4, pp. 399-408, 1996.

[7] J. C. Barton and R. T. Acton, "HLA-A and -B alleles and haplotypes in hemochromatosis probands with HFE C282Y homozygosity in central Alabama," BMC Medical Genetics, vol. 3, article 9, 2002.

[8] M. Costa, E. Cruz, J. C. Barton et al., "Effects of highly conserved major histocompatibility complex (MHC) extended haplotypes on iron and low CD8+ T lymphocyte phenotypes in HFE C282Y homozygous hemochromatosis patients from three geographically distant areas," PLoS ONE, vol. 8, no. 11, Article ID e79990, 2013.

[9] M. Simon, L. Le Mignon, R. Fauchet et al., "A study of 609 HLA haplotypes marking for the hemochromatosis gene: (1) Mapping of the gene near the HLA-A locus and characters required to define a heterozygous population and (2) Hypothesis concerning the underlying cause of hemochromatosis-HLA association," American Journal of Human Genetics, vol. 41, no. 2, pp. 89-105, 1987.

[10] R. Pratiwi, L. M. Fletcher, W. R. Pyper et al., "Linkage disequilibrium analysis in Australian haemochromatosis patients indicates bipartite association with clinical expression," Journal of Hepatology, vol. 31, no. 1, pp. 39-46, 1999.

[11] J. C. Barton, J. C. Barton, and R. T. Acton, "Longer survival associated with HLA-A ${ }^{*} 03, B^{*} 14$ among 212 hemochromatosis probands with HFE C282Y homozygosity and HLA-A and -B typing and haplotyping," European Journal of Haematology, vol. 85 , no. 5 , pp. 439-447, 2010.

[12] K. S. Olsson, B. Ritter, and N. Hansson, "The HLA-A1-B8 haplotype hitchhiking with the hemochromatosis mutation: does it affect the phenotype?" European Journal of Haematology, vol. 79, no. 5, pp. 429-434, 2007.

[13] K. S. Olsson, B. Ritter, and R. Raha-Chowdhury, "HLA-A3$\mathrm{B} 14$ and the origin of the haemochromatosis $\mathrm{C} 282 \mathrm{Y}$ mutation: founder effects and recombination events during 12 generations in a Scandinavian family with major iron overload," European Journal of Haematology, vol. 84, no. 2, pp. 145-153, 2010.

[14] J. K. Siddoo, "Acquired hemolytic anemia associated with hemochromatosis," Archives of Internal Medicine, vol. 93, no. 6, pp. 977-981, 1954.

[15] A. Perdrup and H. Poulsen, "Hemochromatosis and vitiligo," Archives of Dermatology, vol. 90, pp. 34-37, 1964.

[16] C. Q. Edwards, T. M. Kelly, G. Ellwein, and J. P. Kushner, "Thyroid disease in hemochromatosis. Increased incidence in homozygous men," Archives of Internal Medicine, vol. 143, no. 10, pp. 1890-1893, 1983.

[17] W. E. Morris Jr., "Hemochromatosis and celiac sprue. Case report," Journal of the Florida Medical Association, vol. 80, no. 4, pp. 243-245, 1993.

[18] J. C. Barton, B. M. McGuire, and R. T. Acton, "HFE hemochromatosis and hepatic sarcoid," The American Journal of the Medical Sciences, vol. 337, no. 5, pp. 386-390, 2009.

[19] J. F. Ludvigsson, J. A. Murray, P. C. Adams, and M. Elmberg, "Does hemochromatosis predispose to celiac disease? A study of 29,096 celiac disease patients," Scandinavian Journal of Gastroenterology, vol. 48, no. 2, pp. 176-182, 2013.

[20] P. C. Adams and J. C. Barton, "How I treat hemochromatosis," Blood, vol. 116, no. 3, pp. 317-325, 2010.

[21] "Diagnosis and classification of diabetes mellitus," Diabetes Care, vol. 33, supplement 1, pp. S62-S69, 2010. 
[22] J. C. Barton, J. C. Barton, R. T. Acton, J. So, S. Chan, and P. C. Adams, "Increased risk of death from iron overload among 422 treated probands with $H F E$ hemochromatosis and serum levels of ferritin greater than $1000 \mu \mathrm{g} / \mathrm{L}$ at diagnosis," Clinical Gastroenterology and Hepatology, vol. 10, no. 4, pp. 412-416, 2012.

[23] P. J. Scheuer, R. Williams, and A. R. Muir, "Hepatic pathology in relatives of patients with haemochromatosis," The Journal of Pathology and Bacteriology, vol. 84, no. 1, pp. 53-64, 1962.

[24] J. C. Barton, W. W. H. Shih, R. Sawada-Hirai et al., "Genetic and clinical description of hemochromatosis probands and heterozygotes: evidence that multiple genes linked to the major histocompatibility complex are responsible for hemochromatosis," Blood Cells, Molecules, and Diseases, vol. 23, no. 1, pp. 135$145,1997$.

[25] G. King and L. Zeng, "Logistic regression in rare events data," Political Analysis, vol. 9, no. 2, pp. 137-163, 2001.

[26] M. A. Heneghan, K. M. Feeley, F. M. Stevens, M. P. G. Little, and C. F. McCarthy, "Precipitation of iron overload and hereditary hemochromatosis after successful treatment of celiac disease," American Journal of Gastroenterology, vol. 95, no. 1, pp. 298-299, 2000.

[27] A. Turcu, L. Lévêque, P. Bielefeld, J.-F. Besancenot, and P. Hillon, "Adult celiac disease and hemochromatosis," The American Journal of Gastroenterology, vol. 95, no. 12, pp. 3661-3662, 2000.

[28] A. Geier, C. Gartung, I. Theurl et al., "Occult celiac disease prevents penetrance of hemochromatosis," World Journal of Gastroenterology, vol. 11, no. 21, pp. 3323-3326, 2005.

[29] E. Zubizarreta, E. Zapata, and A. Castiella, "Celiac disease and hemochromatosis," European Journal of Gastroenterology and Hepatology, vol. 20, no. 6, p. 589, 2008.

[30] C. Ellervik, T. Mandrup-Poulsen, A. Tybjærg-Hansen, and B. G. Nordestgaard, "Total and cause-specific mortality by elevated transferrin saturation and hemochromatosis genotype in individuals with diabetes: two general population studies," Diabetes Care, vol. 37, no. 2, pp. 444-452, 2014.

[31] G. Tamagno, E. De Carlo, G. Murialdo, and C. Scandellari, "A possible link between genetic hemochromatosis and autoimmune thyroiditis," Minerva Medica, vol. 98, no. 6, pp. 769-772, 2007.

[32] C. M. Dayan and G. H. Daniels, "Chronic autoimmune thyroiditis," The New England Journal of Medicine, vol. 335, no. 2, pp. 99-107, 1996.

[33] E. C. Somers, S. L. Thomas, L. Smeeth, and A. J. Hall, "Are individuals with an autoimmune disease at higher risk of a second autoimmune disorder?" American Journal of Epidemiology, vol. 169, no. 6, pp. 749-755, 2009.

[34] M. L. Friedland and P. Schaefer, "Hemochromatosis, thrombocytopenic purpura, and multiple endocrine disturbances. An unusual association of uncommon disorders is reported," Rhode Island Medical Journal, vol. 63, no. 9, pp. 342-344, 1980.

[35] M. E. Herford, "Haemochromatosis, diabetes, and hyperthyroidism," British Medical Journal, vol. 3, no. 5666, article 359, 1969.

[36] P. C. Adams, "Hereditary hemochromatosis and red cell aplasia," American Journal of Hematology, vol. 45, no. 3, pp. 260-261, 1994.

[37] H. Attout, S. Guez, and C. Sériès, "Association of hereditary hemochromatosis and pernicious anaemia," La Revue de Médecine Interne, vol. 25, no. 10, pp. 759-761, 2004.
[38] B. Bonafoux, L. Henry, C. Delfour et al., "Association of familial pernicious anaemia and hereditary haemochromatosis," Acta Haematologica, vol. 119, no. 1, pp. 12-14, 2008.

[39] J. Mathew, M. Y. Leong, N. Morley, and A. D. Burt, "A liver fibrosis cocktail? Psoriasis, methotrexate and genetic hemochromatosis," BMC Dermatology, vol. 5, article 12, 2005.

[40] J. Schedel, A. Wimmer, A. Friedrich, R. Büttner, J. Schölmerich, and U. Müller-Ladner, "Unusual co-incidence of Heberden's and Bouchard's osteoarthritis, rheumatoid arthritis and haemochromatosis," Rheumatology, vol. 42, no. 9, pp. 1109-1111, 2003.

[41] D. Wernicke, E. Seipelt, W. A. Schmidt, and E. Gromnica-Ihle, "Manifestation of rheumatoid arthritis in a patient with hereditary haemochromatosis," Rheumatology International, vol. 26, no. 10, pp. 939-941, 2006.

[42] R. W. Dunlap Jr., G. A. Hallenbeck, and D. G. Hanlon, "Portal hypertension with sarcoidosis and with hemochromatosis: report of 2 cases with splenectomy and splenorenal anastomosis," Proceedings of the Staff Meetings of the Mayo Clinic, vol. 27, no. 14, pp. 266-272, 1952.

[43] M. van Deuren, J. J. C. Kroot, and D. W. Swinkels, “Time-course analysis of serum hepcidin, iron and cytokines in a C282Y homozygous patient with Schnitzler's syndrome treated with IL1 receptor antagonist," Haematologica, vol. 94, no. 9, pp. 12971300, 2009.

[44] C. Y. Ponsioen, P. C. F. Stokkers, A. R. V. Horst, G. N. J. Tytgat, and S. J. H. Van Deventer, "A patient with hereditary hemochromatosis, ulcerative colitis, and primary sclerosing cholangitis: genetic aspects," European Journal of Internal Medicine, vol. 12, no. 6, pp. 518-521, 2001.

[45] K. R. Parisian, T. P. Plesec, K. D. Fairbanks, A. S. Tavill, and B. Shen, "Concomitant presentation of collagenous sprue and HFE hemochromatosis," Journal of Crohn's and Colitis, vol. 5, no. 4, pp. 369-372, 2011.

[46] G. Candore, D. Lio, G. C. Romano, and C. Caruso, "Pathogenesis of autoimmune diseases associated with 8.1 ancestral haplotype: effect of multiple gene interactions," Autoimmunity Reviews, vol. 1, no. 1-2, pp. 29-35, 2002.

[47] G. S. Cooper, M. L. K. Bynum, and E. C. Somers, "Recent insights in the epidemiology of autoimmune diseases: improved prevalence estimates and understanding of clustering of diseases," Journal of Autoimmunity, vol. 33, no. 3-4, pp. 197-207, 2009.

[48] W. W. Eaton, N. R. Rose, A. Kalaydjian, M. G. Pedersen, and P. B. Mortensen, "Epidemiology of autoimmune diseases in Denmark," Journal of Autoimmunity, vol. 29, no. 1, pp. 1-9, 2007.

[49] J. J. Schweizer, B. M. E. von Blomberg, H. B. Bueno-de Mesquita, and M. L. Mearin, "Coeliac disease in the Netherlands," Scandinavian Journal of Gastroenterology, vol. 39, no. 4, pp. 359-364, 2004.

[50] D. L. Jacobson, S. J. Gange, N. R. Rose, and N. M. H. Graham, "Epidemiology and estimated population burden of selected autoimmune diseases in the United States," Clinical Immunology and Immunopathology, vol. 84, no. 3, pp. 223-243, 1997.

[51] A. Åsberg, K. Hveem, Ø. Krüger, and K. S. Bjerve, "Persons with screening-detected haemochromatosis: as healthy as the general population?" Scandinavian Journal of Gastroenterology, vol. 37, no. 6, pp. 719-724, 2002.

[52] J. C. Barton, C. Leiendecker-Foster, D. M. Reboussin, P. C. Adams, R. T. Acton, and J. H. Eckfeldt, "Thyroid-stimulating hormone and free thyroxine levels in persons with HFE C282Y 
homozygosity, a common hemochromatosis genotype: the HEIRS Study," Thyroid, vol. 18, no. 8, pp. 831-838, 2008.

[53] A. Staii, S. Mirocha, K. Todorova-Koteva, S. Glinberg, and J. C. Jaume, "Hashimoto thyroiditis is more frequent than expected when diagnosed by cytology which uncovers a pre-clinical state," Thyroid Research, vol. 3, no. 1, article 11, 2010.

[54] B. Kaplan, E. N. Pearce, and A. P. Fairwell, "Thyroiditis", in Oxford Textbook of Endocrinology and Diabetes, J. A. H. Wass and P. M. Stewart, Eds., chapter 3.2.7, pp. 432-440, Oxford University Press, Oxford, UK, 2011.

[55] M. J. Simmonds, F. K. Kavvoura, O. J. Brand et al., "Skewed $\mathrm{X}$ chromosome inactivation and female preponderance in autoimmune thyroid disease: an association study and metaanalysis," Journal of Clinical Endocrinology and Metabolism, vol. 99, no. 1, pp. E127-E131, 2014.

[56] J. H. Sheldon, Haemochromatosis, Oxford University Press, London, UK, 1935.

[57] A. J. Silman and M. C. Hochberg, Epidemiology of the Rheumatic Diseases, Oxford University Press, New York, NY, USA, 2001.

[58] C. G. Helmick, D. T. Felson, R. C. Lawrence et al., "Estimates of the prevalence of arthritis and other rheumatic conditions in the United States. Part I," Arthritis \& Rheumatism, vol. 58, no. 1, pp. 15-25, 2008.

[59] R. Rull and R. Schumacher Jr., "The arthropathy of hemochromatosis," in Hemochromatosis: Genetics, Pathophysiology, Diagnosis and Treatment, J. C. Barton and C. Q. Edwards, Eds., chapter 24, pp. 258-267, Cambridge University Press, Cambridge, UK, 2000.

[60] L. E. Dean, G. T. Jones, A. G. MacDonald, C. Downham, R. D. Sturrock, and G. J. Macfarlane, "Global prevalence of ankylosing spondylitis," Rheumatology, vol. 53, no. 4, pp. 650657, 2014.

[61] M. A. Khan, W. E. Braun, I. Kushner, D. E. Grecek, W. A. Muir, and A. G. Steinberg, "HLA B27 in ankylosing spondylitis: differences in frequency and relative risk in American Blacks and Caucasians," Journal of Rheumatology Supplement, vol. 3, pp. 339-343, 1977.

[62] J. D. Reveille, "HLA-B27 and the seronegative spondyloarthropathies," The American Journal of the Medical Sciences, vol. 316, no. 4, pp. 239-249, 1998.

[63] E. G. Bywaters, E. B. Hamilton, and R. Williams, "The spine in idiopathic haemochromatosis," Annals of the Rheumatic Diseases, vol. 30, no. 5, pp. 453-465, 1971.

[64] C. H. Walsh, "Non-diabetic endocrinopathy in hemochromatosis," in Hemochromatosis: Genetics, Pathogenesis, Diagnosis and Treatment, J. C. Barton and C. Q. Edwards, Eds., chapter 26, pp. 278-289, Cambridge University Press, Cambridge, UK, 2000.

[65] R. A. MacDonald and G. K. Mallory, "Hemochromatosis and hemosiderosis. Study of 211 autopsied cases," Archives of Internal Medicine, vol. 105, pp. 686-700, 1960.

[66] W. R. Bezwoda, Bothwell, and L. A. van der Walt, "An investigation into gonadal dysfunction in patients with idiopathic haemochromatosis," Clinical Endocrinology, vol. 6, no. 5, pp. 377-385, 1977.

[67] C. Varela, A. Hurtado, D. Boixeda et al., "Gonadal and pituitary function in idiopathic hemochromatosis," Medicina Clinica, vol. 81, no. 14, pp. 606-609, 1983.

[68] J. C. Barton, N. H. Barton, and T. J. Alford, "Diagnosis of hemochromatosis probands in a community hospital," The American Journal of Medicine, vol. 103, no. 6, pp. 498-503, 1997.
[69] M. S. Murphy and C. H. Walsh, "Thyroid function in haemochromatosis," Irish Journal of Medical Science, vol. 173, no. 1, pp. 27-29, 2004.

[70] A. E. Stocks and L. W. Powell, "Pituitary function in idiopathic haemochromatosis and cirrhosis of the liver," The Lancet, vol. 300, no. 7772, pp. 298-300, 1972.

[71] L. J. Siemons and C. H. Mahler, "Hypogonadotropic hypogonadism in hemochromatosis: recovery of reproductive function after iron depletion," Journal of Clinical Endocrinology and Metabolism, vol. 65, no. 3, pp. 585-587, 1987.

[72] R. Gama, M. J. Smith, J. Wright, and V. Marks, "Hypopituitarism in primary haemochromatosis; recovery after iron depletion," Postgraduate Medical Journal, vol. 71, no. 835, pp. 297-298, 1995.

[73] H. Wilkinson, "Haemochromatosis associated with arthritis and hypopituitarism," Annals of Clinical Biochemistry, vol. 33, no. 2, pp. 171-173, 1996.

[74] M. Hudec, M. Grigerova, and C. H. Walsh, "Secondary hypothyroidism in hereditary hemochromatosis: recovery after iron depletion," Thyroid, vol. 18, no. 2, pp. 255-257, 2008.

[75] A. E. Stocks and F. I. R. Martin, "Pituitary function in haemochromatosis," The American Journal of Medicine, vol. 45, no. 6, pp. 839-845, 1968.

[76] K. Boelaert, P. R. Newby, M. J. Simmonds et al., "Prevalence and relative risk of other autoimmune diseases in subjects with autoimmune thyroid disease," The American Journal of Medicine, vol. 123, no. 2, pp. 183-189, 2010.

[77] J. Wiebolt, R. Achterbergh, A. den Boer et al., "Clustering of additional autoimmunity behaves differently in Hashimoto's patients compared with Graves' patients," European Journal of Endocrinology, vol. 164, no. 5, pp. 789-794, 2011.

[78] M. Cindoruk, I. Yetkin, T. Karakan, and U. Kandilci, “The prevalence of autoimmune hepatitis in Hashimoto's thyroiditis in a Turkish population," Acta Gastro-Enterologica Belgica, vol. 65, no. 3, pp. 143-145, 2002.

[79] L. M. Teixeira, R. Nisihara, S. R. D. R. Utiyama et al., "Screening of celiac disease in patients with autoimmune thyroid disease from Southern Brazil," Arquivos Brasileiros de Endocrinologia \& Metabologia, vol. 58, no. 6, pp. 625-629, 2014.

[80] G. Radetti, C. Paganini, L. Gentili et al., "Frequency of Hashimoto's thyroiditis in children with type 1 diabetes mellitus," Acta Diabetologica, vol. 32, no. 2, pp. 121-124, 1995.

[81] E. McCanlies, L. A. O’Leary, T. P. Foley et al., "Hashimoto's thyroiditis and insulin-dependent diabetes mellitus: differences among individuals with and without abnormal thyroid function," Journal of Clinical Endocrinology and Metabolism, vol. 83, no. 5, pp. 1548-1551, 1998.

[82] P. S. N. Menon, B. Vaidyanathan, and M. Kaur, "Autoimmune thyroid disease in Indian children with type 1 diabetes mellitus," Journal of Pediatric Endocrinology and Metabolism, vol. 14, no. 3, pp. 279-286, 2001.

[83] E. Biró, Z. Szekanecz, L. Czirjk et al., "Association of systemic and thyroid autoimmune diseases," Clinical Rheumatology, vol. 25, no. 2, pp. 240-245, 2006.

[84] H. Morimoto, Y. Kato, Y. Ishida et al., "Primary biliary cirrhosis and chronic pancreatitis in a patient with ulcerative colitis," Nihon Shokakibyo Gakkai Zasshi, vol. 81, no. 1, pp. 117-120, 1984.

[85] A. Bush, H. Mitchison, R. Walt, J. H. Baron, A. W. Boylston, and J. A. Summerfield, "Primary biliary cirrhosis and ulcerative colitis," Gastroenterology, vol. 92, no. 6, pp. 2009-2013, 1987.

[86] F. Tada, M. Abe, H. Nunoi et al., "Ulcerative colitis complicated with primary biliary cirrhosis," Internal Medicine, vol. 50, no. 20, pp. 2323-2327, 2011. 
[87] J.-M. Anaya, L. Gómez, and J. Castiblanco, "Is there a common genetic basis for autoimmune diseases?" Clinical and Developmental Immunology, vol. 13, no. 2-4, pp. 185-195, 2006.

[88] M. P. Desai and S. Karandikar, "Autoimmune thyroid disease in childhood: a study of children and their families," Indian Pediatrics, vol. 36, no. 7, pp. 659-668, 1999.

[89] M. Dittmar, C. Libich, T. Brenzel, and G. J. Kahaly, "Increased familial clustering of autoimmune thyroid diseases," Hormone and Metabolic Research, vol. 43, no. 3, pp. 200-204, 2011.

[90] G. Zandman-Goddard and Y. Shoenfeld, "Hyperferritinemia in autoimmunity," The Israel Medical Association Journal, vol. 10, no. 1, pp. 83-84, 2008.

[91] V. Herbert, E. Jayatilleke, S. Shaw et al., "Serum ferritin iron, a new test, measures human body iron stores unconfounded by inflammation," Stem Cells, vol. 15, no. 4, pp. 291-296, 1997.

[92] P. Nielsen, U. Günther, M. Dürken, R. Fischer, and J. Düllmann, "Serum ferritin iron in iron overload and liver damage: correlation to body iron stores and diagnostic relevance," Journal of Laboratory and Clinical Medicine, vol. 135, no. 5, pp. 413-418, 2000.

[93] D. A. Lipschitz, J. D. Cook, and C. A. Finch, "A clinical evaluation of serum ferritin as an index of iron stores," The New England Journal of Medicine, vol. 290, no. 22, pp. 1213-1216, 1974.

[94] D. J. Piñero, J. Hu, B. M. Cook, R. C. Scaduto Jr., and J. R. Connor, "Interleukin- $1 \beta$ increases binding of the iron regulatory protein and the synthesis of ferritin by increasing the labile iron pool," Biochimica et Biophysica Acta-Molecular Cell Research, vol. 1497, no. 3, pp. 279-288, 2000.

[95] S. J. Walsh and L. M. Rau, "Autoimmune diseases: a leading cause of death among young and middle-aged women in the United States," American Journal of Public Health, vol. 90, no. 9, pp. 1463-1466, 2000.

[96] C. Niederau, R. Fischer, A. Sonnenberg, W. Stremmel, H. J. Trampisch, and G. Strohmeyer, "Survival and causes of death in cirrhotic and in noncirrhotic patients with primary hemochromatosis," The New England Journal of Medicine, vol. 313, no. 20, pp. 1256-1262, 1985.

[97] G. S. Cooper, J. Wither, T. Mckenzie et al., "The prevalence and accuracy of self-reported history of 11 autoimmune diseases," Journal of Rheumatology, vol. 35, no. 10, pp. 2001-2004, 2008.

[98] S. C. L. Gough and M. J. Simmonds, "The HLA region and autoimmune disease: associations and mechanisms of action," Current Genomics, vol. 8, no. 7, pp. 453-465, 2007. 


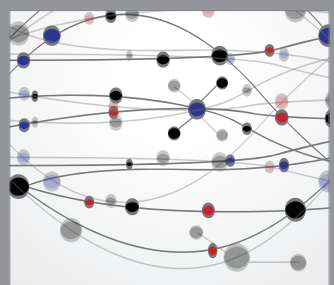

The Scientific World Journal
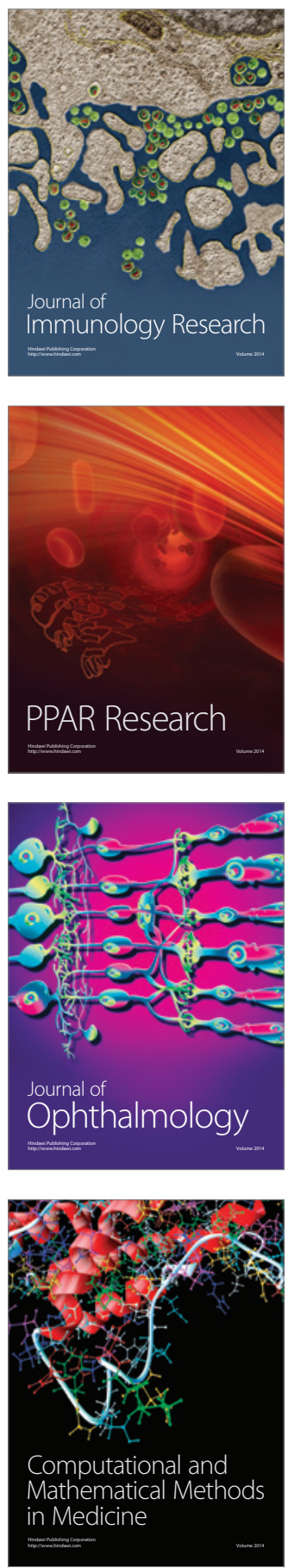

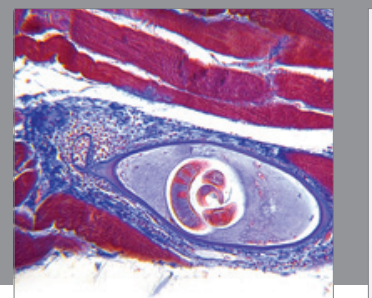

Gastroenterology

Research and Practice
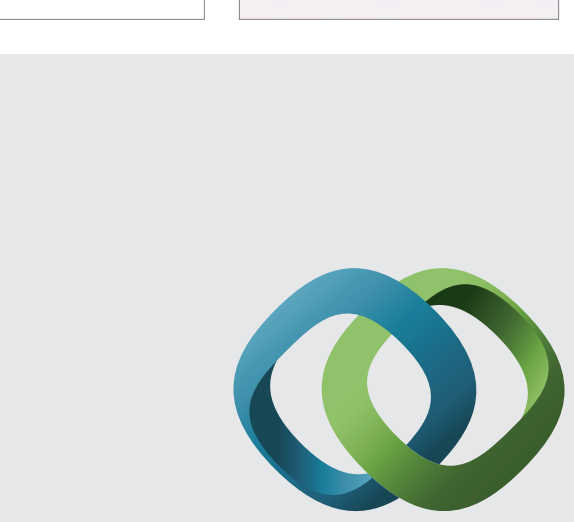

\section{Hindawi}

Submit your manuscripts at

http://www.hindawi.com
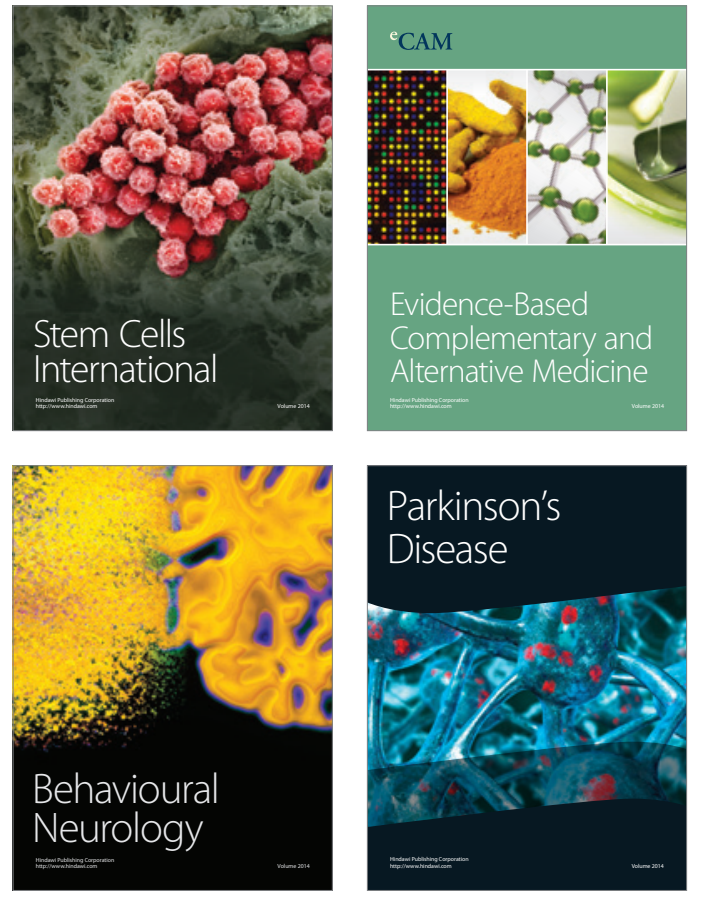
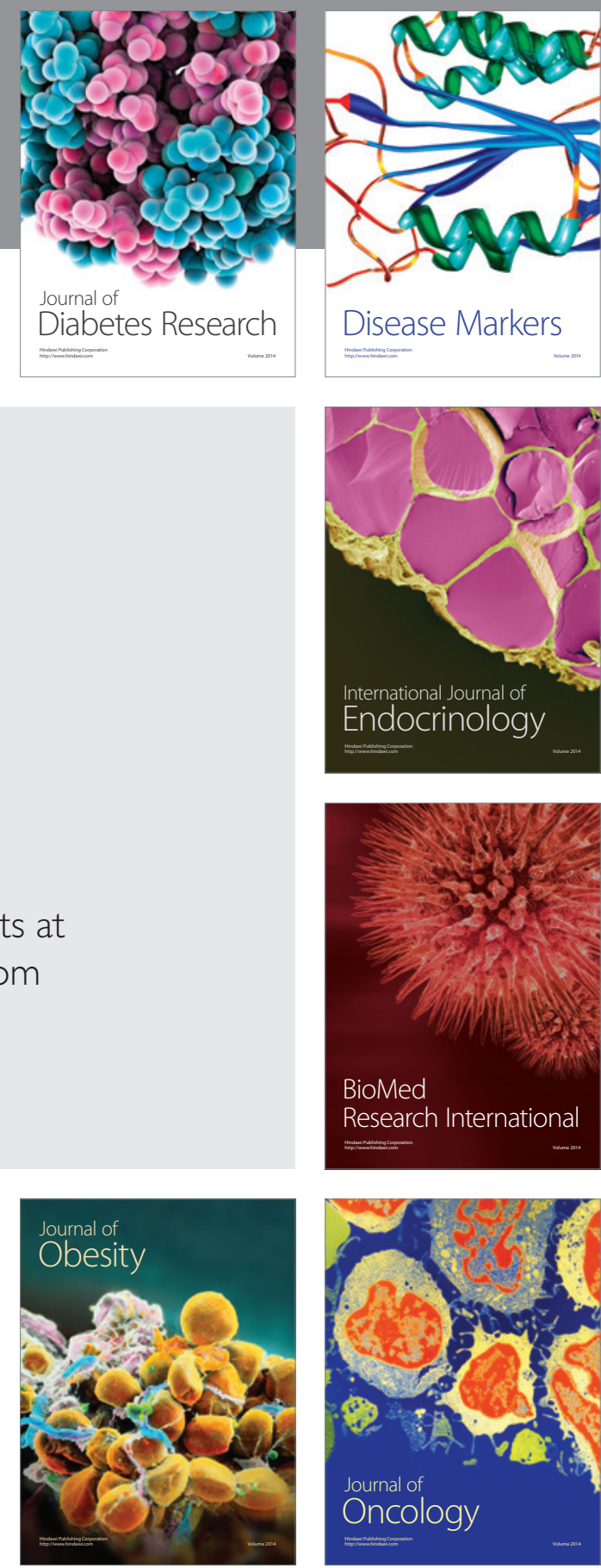

Disease Markers
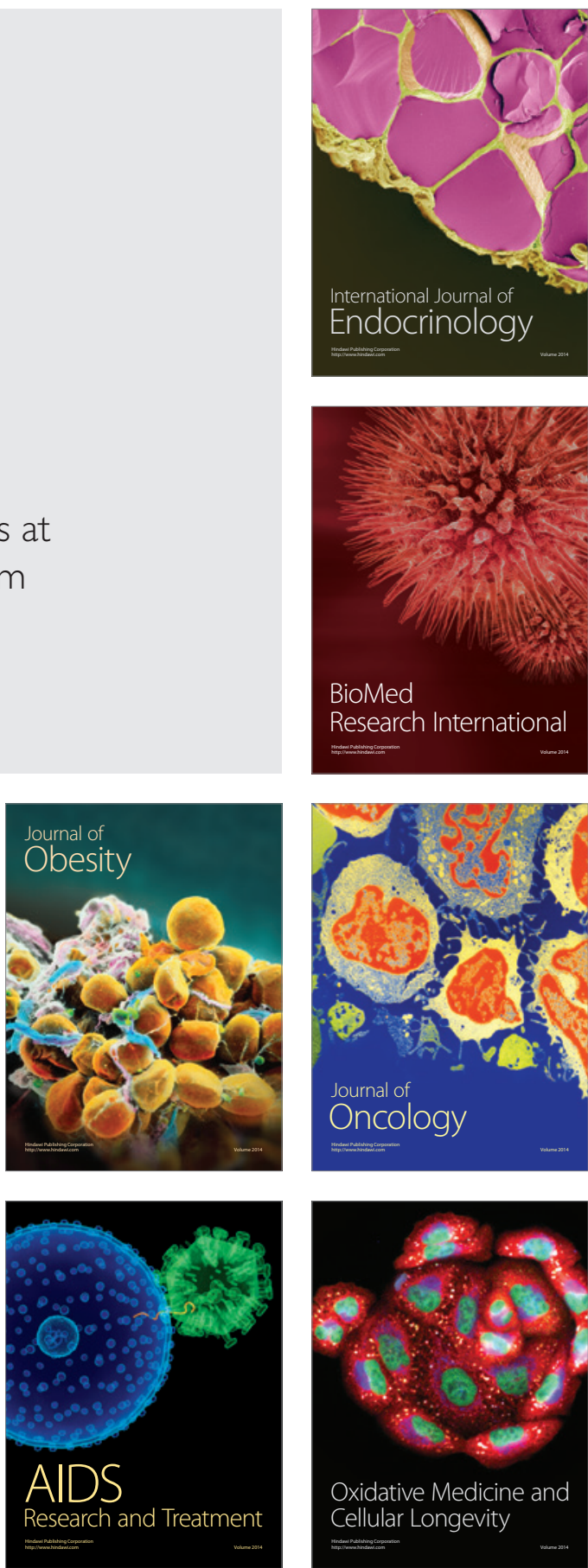